\title{
John Hunter (1728-1793) and his legacy to science
}

\author{
Yasemin Kaya $^{1} \cdot$ Alper Sindel $^{2}$
}

Received: 29 June 2015 / Accepted: 20 July 2015 / Published online: 5 August 2015

(C) Springer-Verlag Berlin Heidelberg 2015

\section{His life}

John Hunter was born in 1728 in Kilbride East, Lanarkshire, Scotland, as the youngest child of a family of ten children. John's father died in 1741 and he was thus left to care for his mother. When John was about 17, young John moved to London to study under William Hunter (1718-1783), his 10-yearelder brother and was already an anatomist and obstetrician [24]. He studied as a dissector in William's Anatomy School in Covent Garden in 1748 and showed his abilities on cadaver dissections. In 1749, he became a lecturer and demonstrator in anatomy [11]. His brother obtained permission for him to attend the Chelsea Hospital under the supervision of Dr. William Cheselden (1688-1752), Hunter's first master in surgery and the most celebrated surgeon of his time. On the retirement of Dr. William Cheselden from Chelsea Hospital, Hunter entered as surgeon's pupil at St. Bartholomew's Hospital and became a pupil of Percivall Pott (1714-1788) [17]. During his studies under the aforementioned scientists, John made a great progress on dissection. In 1753, as an award of his progress and an honor bestowed upon his mentor Percivall Pott, Hunter was elected Master of Anatomy at Surgeon's Hall [3].

During the Seven Years' War (1756-1763) with France, Hunter was commissioned as an army surgeon in Belle Isle and Portugal. He acquired surgical skills and experienced on

Yasemin Kaya

kayayasemin07@outlook.com

Alper Sindel

dtalpesindel@gmail.com

1 Department of Anatomy, Akdeniz University Faculty of Medicine, 07070 Antalya, Turkey

2 Department of Oral and Maxillofacial Surgery, Akdeniz University Faculty of Dentistry, 07070 Antalya, Turkey gunshot wounds and inflammation [11]. He began to collect materials on those issues which published posthumously in 1794 [15]. On his return to England in 1763, he began to build up his private practice. In 1767, he was elected as a Fellow of the Royal Society [22]. He published the first part of his Treatise on the teeth in May $1771[12,19]$. Two months later, he married Anne Home (1742-1821), a daughter of an old Scottish family [8]. In 1768, he was elected Surgeon to St. George's Hospital and he was appointed as SurgeonExtraordinary to King George III in 1776. In 1786, he won the Copley Medal, the highest award of the Royal Society [24].

While meeting of the Board of Governors of St. George's Hospital, he collapsed and died on 16 October 1793. There are some conflicts on the reason of his death. The autopsy demonstrated lesions in his aorta compatible with his self-induced syphilis [22]. Others argued that there was no autopsy evidence of syphilis but evidence only of advanced arteriosclerotic vascular disease $[6,10]$. He was initially buried in a crypt of the Church of St. Martin-in-the-Field. His remains were transferred to Westminster Abbey in February 1859 [24].

\section{His contributions to medicine}

Hunter performed an important experiment on the effects of ligation of the blood supply from the carotid artery to the antlers [23]. After the operation, he observed how the antler of the stag became cold and stopped growing. He was really surprised that a week later, the antler became warm and then he approved this new observation by arterial injection [22]. He finally understood how the body compensated the insult by increasing the collateral circulation to the antlers [7]. Results of this experiment were able to give him valuable knowledge to cure popliteal aneurysm by proximal ligation of the femoral 
artery (in a canal bears his name, Hunter's canal) although his teacher Percivall Pott (1714-1788) and several contemporary surgeons claimed amputation as being the best treatment for popliteal aneurysms $[9,22]$.

John Hunter was also known for his contributions on venereal diseases [14]. He inoculated a man (not himself as claimed by some authors) with gonorrheal pus from a patient's chancre [10]. He tried to observe the course of the disease and treated the symptoms with mercurial ointments. Gubernaculum, testicular descent, and the importance of the androgens on prostatic development were also described by Hunter [5].

He also defined some characteristics of the human anatomy. Two important contributions of the John Hunter on anatomy of the human body can be documented. He demonstrated that the lymphatic system was separate from the blood system. Contrary to the general acceptance of his contemporaries, he described that the blood circulations of a human fetus and its mother were separate and not joined directly together. This contribution led to fall out with his elder brother William since no recognition was given to John's contribution in Williams' book [16]. William Hunter gave general acknowledgements to John's assistance and did not mention his name in the discovery of this particular subject [19]. He also proved that the testicle normally completed its descent into the scrotum by 8 months. This work led to a conflict with Dr. Percivall Pott [22].

John Hunter had an interest on comparative anatomy and collected many animals and plant species to found a comprehensive museum of comparative anatomy [2]. He dissected cadavers of many animal species and thousands of which are preserved in the Hunterian Museum.

Hunter made important contributions to medicine. He helped in transforming surgery from a trade to an experimental science. Sir James Paget (1814-1899) often acknowledged Hunter: "Hunter made us gentlemen. When he entered surgery it was a trade; when he died it had become a science" [3]. John Hunter was also a great teacher of outstanding physicians and surgeons, such as Edward Jenner (1749-1823), Philip Syng Physick (1768-1837), William Shippen Jr. (1736-1808), John Morgan (1735-1789), John Abernethy (1764-1831), Astley Cooper (1768-1841), Henry Cline (1750-1827), James Parkinson (1755-1824), and Wright Post (1766-1828) [7]. His talks with his pupil Edward Jenner such as "think your solution is just; but why think, why not try the experiment?" was evidence of a stimulating teacher to establish experimental works [3].

\section{His contribution on trigeminal neuralgia}

Financial issues were also big problems in Hunter's life. John Hunter's engagement in dentistry for 6 years may be easily understood. During his practice in dentistry, he collected several experience and knowledge on teeth [21]. Based on his experience in dentistry, Hunter revolutionized dentistry in the Great Britain and published the first part of his Treatise on the teeth in May $1771[12,19]$. This book contained the natural history of those organs in their healthy state [19]. In 1778 , the second part of the book was published in which he furnished comprehensive views of the physiology and pathology of the teeth (Fig. 1, cover figure). In this second part of his treatise, he wrote a special chapter for nervous diseases of the teeth [13]. In this special chapter, he described trigeminal neuralgia with the following paragraph:

This pain is seated in some one part of the Jaws. As simple pain demonstrates nothing, a Tooth is often suspected, and is perhaps drawn out; but still the pain continues, with this difference however, that it now seems to be in the root of the next Tooth: it is then supposed either by the patient or the operator, that the wrong Tooth was extracted; wherefore, that in which the pain now seems to be, is drawn, but with as little benefit. I have known cases of this kind, where all the Teeth of the affected side of the Jaw, have been drawn out, and the pain has continued in the Jaw; in others, it has had a different effect, the sensation of pain has become more diffused, and has at last, attacked the corresponding side of the tongue. In the first case, I have known it recommended to cut down upon the Jaw, and even to perforate and cauterize it, but all without effect. Hence it should appear, that the pain, in question, does not arise from any disease in the part, but entirely a nervous affection [13].

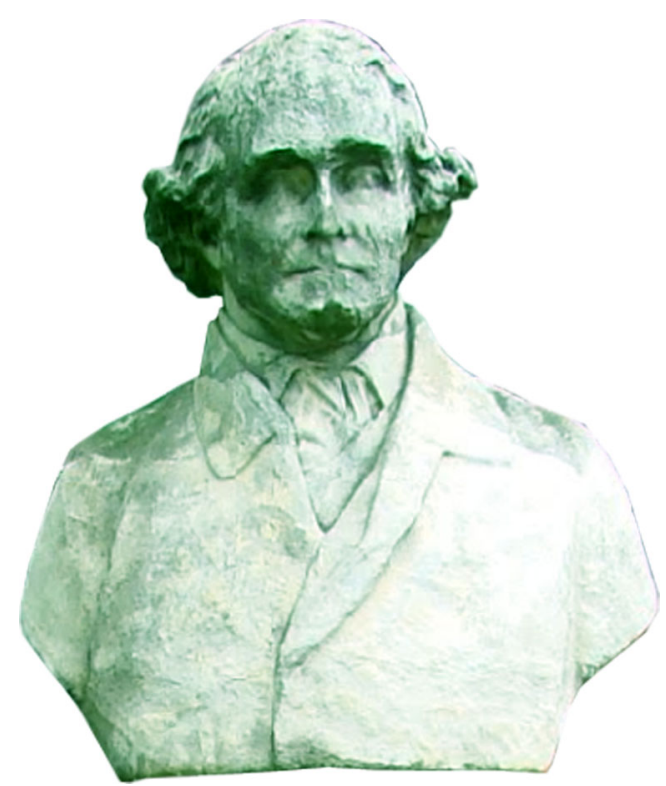

Fig. 1 and cover figure John Hunter's bust in Leicester Square, London. The bust was sculptured by Thomas Woolner (1874) 
For better understanding of Hunter's contribution on trigeminal neuralgia, one should think within the context of what was known or what was the tradition for treatment of the trigeminal neuralgia. In 1773, John Fothergill gave the first full and accurate description of trigeminal neuralgia in his article entitled On a Painful Affliction of the Face [20]. Fothergill reported typical features of the condition in detail, including paroxysms of unilateral facial pain, triggered by eating or speaking or touch, starting and ending abruptly, and associated with anxiety [18]. Nicolas André coined the term tic douloureux in 1756 [1]. Although André was considered as a charlatan by his contemporaries, he believed that the pain of tic douloureux arose from compression of sensory peripheral nerve branches [4]. He compressed proximal end of the involved nerve with tweezers to observe reproduction of the pain and tried to confirm this hypothesis by this empirical method. He also tried to remove scarred adhesions, possible cause of the pain, from the nerve with a caustic solution of mercury water [4].

Hunter's contemporaries usually performed unfortunate and useless extraction of an entire row of teeth to relieve the pain of the affected side of the jaw. This was a diagnostic blunder. This is why Hunter's contribution on the nature of trigeminal neuralgia as an entirely nervous system disease should be considered as a milestone in the treatment of the trigeminal neuralgia. Studies of Sir Charles Bell (1774-1842) and François Magendie (1783-1855) on functions of the cranial nerves and on description of the distinction of the sensory function of the fifth nerve helped to localize the anatomic locus for the pain.

\section{Conclusion}

It is difficult to label John Hunter as an anatomist, surgeon, physician, pathologist, and biologist. John Hunter was beyond these titles. He will be remembered by his important contributions on our understanding of basic physiologic actions of blood, inflammation and gunshot wounds, venereal disease, experimental surgery, and trigeminal neuralgia.

Acknowledgments The authors thank Akdeniz University Research Project Unit for their support.

Conflict of interest The authors declare that they have no competing interests.

\section{References}

1. André N (1756) Observations pratiques sur les maladies de l'urèthre et sur plusiers faits convulsifs, \& la guérison de plusiers maladies chirurgicales, avec la décomposition d'un remède propre à réprimer la dissolution gangréneuse \& cancéreuse, \& à la réparer; avec des principes qui pourront servir à employer les différens caustiques. Delaguette, Paris

2. Bland-Sutton J (1923) The Hunterian Oration on John Hunter (1728-1793): His Affairs, Habits, and Opinions: delivered at the Royal College of Surgeons, February 14th, 1923. Br Med J 1:267273

3. Bloch H (1986) John Hunter, Esq, FRCS (1728-1793). Am J Surg 151:640-642

4. Brown JA, Coursaget C, Preul MC, Sangvai D (1999) Mercury water and cauterizing stones: Nicolas Andre and tic douloureux. J Neurosurg 90:977-981. doi:10.3171/jns.1999.90.5.0977

5. Challacombe B, Wheatstone S, Dasgupta P, Challacombe S (2010) John Hunter (1728-1793) and the birth of scientific urology. J Urol $183: \mathrm{e} 438$

6. Ellis H (2010) Letter to the Editor. John Hunter. J Med Biogr 18:61. doi:10.1258/jmb.2009.009099, author reply 61

7. Evans CH (2007) John Hunter and the origins of modern orthopaedic research. J Orthop Res 25:556-560. doi:10.1002/jor.20386

8. Fu L (2010) Medicine and music: a note on John Hunter (1728-93) and Joseph Haydn (1732-1809). J Med Biogr 18:115-122. doi:10. 1258/jmb.2009.009088

9. Galland RB (2007) Popliteal aneurysms: from John Hunter to the 21st century. Ann R Coll Surg Engl 89:466-471. doi:10.1308/ 003588407X183472

10. Gladstein J (2005) Hunter's chancre: did the surgeon give himself syphilis? Clin Infect Dis 41:128. doi:10.1086/430834, author reply 128-129

11. Herman JR (1978) Syphilis and gonorrhea are one disease: John Hunter (1760). Int J Dermatol 17:252-255

12. Hunter $\mathrm{J}(1771)$ The natural history of the human teeth, explaining their structure, use, formation, growth and diseases. Part 2. J. Johnson., London

13. Hunter J (1778) A practical treatise on the diseases of the teeth, intended as a supplement to the natural history of those parts. J. Johnson, London

14. Hunter J (1788) A treatise on the venereal disease. Mr G. Nicol, Pall-Mall, London

15. Hunter J (1794) Treatise on the blood, inflammation and gunshot wounds. G. Nicol, London

16. Hunter W (1774) Anatomia uteri humani gravidi tabulis illustrata [The anatomy of the human gravid uterus exhibited in figures]. John Baskerville, Birmingham

17. Maxwell B (1987) John Hunter: the first surgical scientist. Can J Surg 30:68-71

18. Nurmikko TJ, Eldridge PR (2001) Trigeminal neuralgia - pathophysiology, diagnosis and current treatment. Br J Anaesth 87: 117-132

19. Ottley D (1835) The life of John Hunter. F.R.S., Longman, London

20. Pearce JM (2003) Trigeminal neuralgia (Fothergill's disease) in the 17th and 18th centuries. J Neurol Neurosurg Psychiatry 74:1688

21. Qvist G (1979) Hunterian Oration, 1979. Some controversial aspects of John Hunter's life and work. Ann R Coll Surg Engl 61: 219-223

22. Raffensperger JG (2012) Children's surgery: a worldwide history. McFarland \& Co, Jafferson, North Carolina

23. Stevenson LG (1948) The stag of Richmond Park: a note on John Hunter's most famous animal experiment. Bull Hist Med:467-475

24. Tan SY, Yeow ME (2004) John Hunter (1728-1793): founder of scientific surgery. Singap Med J 45:196-198 